Journal of Engineering and Fundamentals

Vol. 2(2), pp. 24-29, December, 2015

Available online at http://www.tjef.net

ISSN: 2149-0325

http://dx.doi.org/10.17530/jef.15.13.2.2

\title{
Biogas from Biodegradable Kitchen Waste
}

\author{
Pradeep Virupakshappa Badiger*, Rahul Kedarnath Badiger, \\ Mallikarjun Nagur, Manjunath Ashok Vijapur, \\ Shiraganahalli Honnaiah Manjunath
}

Department of Mechanical Engineering, Sapthagiri College of Engineering Bangalore560090

Article history

Received:

21.07.2015

Received in revised form: 03.09.2015

\section{Accepted:}

04.09.2015

Key words: biogas; scrubber; methane;hydrogen and Carbon dioxide
This paper describes about production of biogas from biodegradable waste, an energy resource for the next generation in the upcoming future. The paper defines taking biogas production using kitchen waste into account, explains the need for biogas, and outlines the benefits of biogas, taking facts and figures into consideration. Biogas can be the future resources which are much more ecofriendly and safer to use, leading to a greener tomorrow. Today world is on the verge of major disaster due to the use of conventional fuels as primary fuels. In order to avoid it, it has become our top priority to come with such eco-friendly and flourishing alternative fuels which are available in abundance and easy to harness and can be used as primary fuels of future. This biogas plant can be replicated in an available smaller space and in advocate temperatures. It concludes that to increase the production of biogas from kitchen waste, rice waste should mix with cow dung in 3:2 ratio, with considerable lesser amount of other kitchen waste and also by maintaining the $\mathrm{pH}$ of 6.2-6.5. Calorific value is increased by passing the produced gas through scrubber. The calorific value which we obtained is $32.21 \mathrm{MJ} / \mathrm{kgk}$ which good enough to reduce the requirement of LPG. 


\section{Introduction}

Our planet earth was formed approximately 4.5 billion years age from sun, earth consisted of a vast amount of resources and climatic condition good enough for the evolution and sustenance of life. With the evolution of life on planets, came the human race. Human race being the most intelligent one started utilizing the vast resources of earth for the sustenance and development of its race. Previous to the incoming of humans on earth, a large number of different species had been laid down in the different layers of earth's crust, resulting in transformation of them into fossil fuels under high pressure and temperature. Human race started utilizing these fossils for the benefit of its sustenance and development which ultimately resulted in the misbalance of the ecosystem, which is being experienced in the form of global warming and its effects on earth's environment. In order to save our ecosystem from the global warming, we human are shifting towards a new kind of fuels ,which are much more eco-friendly, cheap and are found in abundance which are known as alternate fuels like biogas.

Biogas is the non-conventional and that can be harnessed from eco-system without damage to the environment. One of the most important characteristics of biogas is that they directly or indirectly affect the eco-system to a small extent, when compared with conventional fuels (petroleum, coal, wood, uranium and etc.).

Some of the other alternate fuels are:

- Biodiesel

- Ethanol

- Hydrogen

\section{Need for alternate fuels}

The need to switch over from conventional fuels to alternate fuels is due to the fact that fossil fuel and other conventional fuels are non-renewable. Once utilized, they can't be recycled again. As a result of emission of $\mathrm{CO}_{2}$, they resulted in global warming. The main factor affecting the global warming due to conventional fuels is carbon di oxide. Another need for the usage of alternative fuels is the need of sustainable development of the present world. In order to maintain the delicate balance of the eco system.

\section{Avialabity and Technological Enhancement:}

When it comes to the availability of resources for alternate fuels, there are lot of sources present in the environment like water, agricultural waste, sewage water, domestic waste, food processing waste, fermented crops, sugar industry waste, sunlight, wind, biomass and etc. The most important characteristics of these sources are that they consist of large amount of energy hidden in them which is being wasted. In order to utilize it, we not only need high level of technology but we also need proper management of these resources. Though we have a large amount of resources for alternate fuels, but the amount of resource utilization varies over technological input of by different countries. As far as utilization is concerned the amount of resource utilized is largest in developed countries followed by developing countries and at the last comes under-developed countries. With the increase in technology, the amount of resources utilized for alternative fuels will also increase in upcoming future. At present billions of dollars of money is being spent on the research and development on eco-friendly fuels oriented technology in various research institutions and laboratories in world.

\section{Biogas}

It is a gas that is generated by anaerobic decomposition of organic matter, which on 
ignition releases energy In the form of heat. Biogas mainly is a mixture of methane and little amount of hydrogen sulphide, ammonia and carbon dioxide. Biogas is a clean, slow burning gas. It can be prepared by decomposition of mixture of cow dung, food processing waste, piggery waste, algae, crop residues, poultry waste etc. The cellulosic organic material of animal or plant origin for raw material with high potential for biogas generation. The decomposition takes place in a pit covered by a lid or wall, known as biogas plant. The slurry left over after the biogas generation can be used as manure and fertilizers. There are three methods by which biogas can be generated. They are digestion, pyrolysis and hydro- gasification. The calorific value of bio gas ranges from $21000 \mathrm{KJ} / \mathrm{kg}$ to $35028 \mathrm{KJ} / \mathrm{kg}$.

\section{Design and fabrication:}

We get a left out food in hostel ranging from $2 \mathrm{~kg}$ to $20 \mathrm{~kg}$ per day. So for over available wastes capacity of digester required is calculated as follows:

Volume of Digester $=$ daily feed in $(\mathrm{m} 3 /$ day $) *$ retention time (day).

Volume of digester (theoretical) = $\mathrm{L}[(20 \mathrm{~kg} /$ day $) /(0.9 * 1000 \mathrm{~kg} / \mathrm{m} 3)]] 30$ day $=0.666 \mathrm{~m}^{3}$

By theoretically we got a value 660 liter capacity digester tank is required for the feed of $2-20 \mathrm{~kg} /$ day, but practically we got the digester tank of capacity of 750 liter which is of calculated in the below.

Volume of digester (practical) $=\Pi R^{2} h \mathrm{~m}^{3}=\Pi * 0.52 * 1 \mathrm{~m}^{3}=0.785 \mathrm{~m}^{3}$

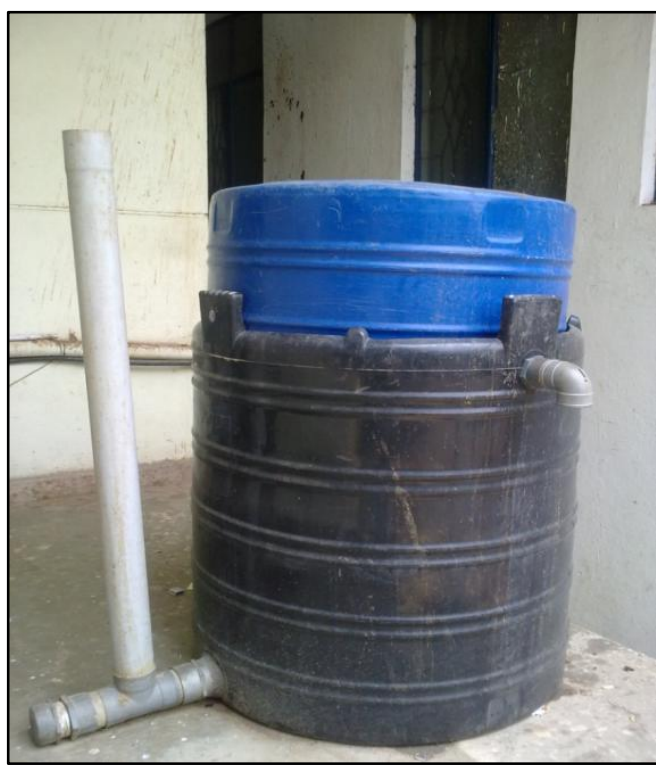

Fig 1. Typical Biogas plant installed in hostel premises.

\section{Methodology:}

1. Separating dry wastes from kitchen waste: We separated the waste from kitchen as dry and wet waste, all dry waste like dry layers of onion is removed dry part of vegetable is removed.

2. Only wet rice waste, left out waste of vegetables taken for the biogas production.

3. Adequate amount of cow dung is mixed with grinded waste: The waste we got from step [1] is mixed with equal amount of water and equal amount of cow dung.

4. Mixture is fed to the digester: The mixture of cow dung, kitchen waste and water is properly stirred and is fed to the digester.

5. The cycle is repeated for every two days: The above step [1] to [3] is repeated for every 2 days

6. Amount of gas produced is tested every day: Thus the gas is produced

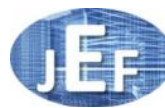


and amount of gas produced is checked every day by burning the biogas.

\section{Changing the factors affecting in order to increase the gas production \\ pH}

- $\mathrm{pH}$ value of the slurry changes at various states of digestion.

- The optimum $\mathrm{pH}$ for the slurry is maintained at 6.5 .

- There was considerable increase in the biogas production feeding the waste rice with cow dung compare to other wastes.

- We maintained $\mathrm{pH}$ value constant by adding b $1 \% \mathrm{~N} \mathrm{HCl}$ to the slurry so we found the maximum yield.

\section{Temperature}

- The optimum temperature for the production of biogas is $35^{\circ} \mathrm{C}-45^{0} \mathrm{C}$.

- The atmospheric temperature is $35^{\circ} \mathrm{C}$ due to summer there is no need to maintain the temperature

\section{Feeding rate}

- Initially we added cow dung in water in equal ratio of 1:1.

- later we added cow dung with waste vegetables and rice wastes in various proportions cow dung:(waste vegetables/ rice waste)::3:3, 3:2 and $2: 3$ analyzed the production of biogas

- We found that production of biogas is maximum by feeding rice waste in the ratio of 2:3.

\section{Purification of Biogas}

- The produced biogas is passed through the scrubber.

- The scrubber is a device which is made up of limewater in which gas is passed in order to purify.

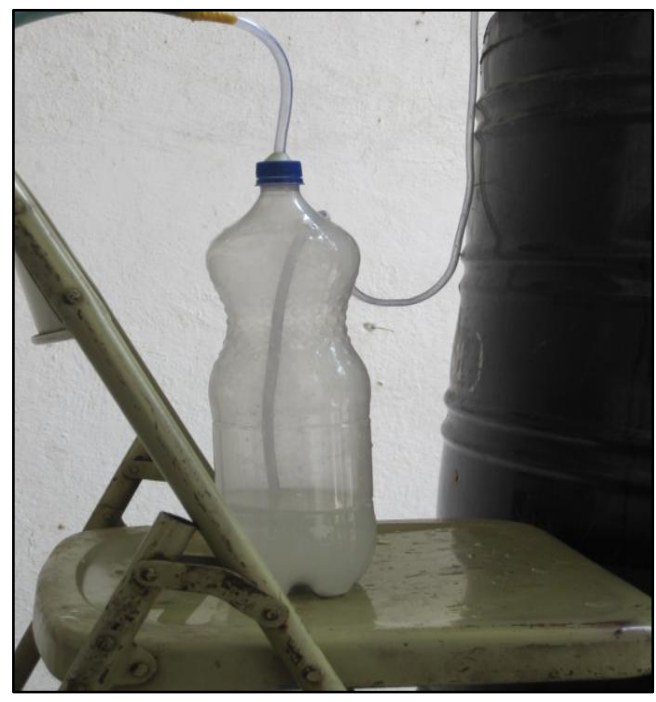

Fig 2. Scrubber used to purify Biogas

- Biogas which consists of methane $\left(\mathrm{CH}_{4}\right)$ and carbon dioxide $\left(\mathrm{CO}_{2}\right)$ as major components.

- In order to reduce the carbon dioxide in biogas it is passed through lime water in which carbon will react with calcium oxide in order to produce calcium carbonate.

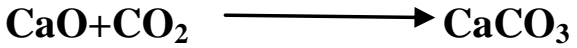

- All the carbon content in biogas is reduced

- $11 \%$ of Methane content is improved using the scrubber.

\section{Benefits of biogas}

- Conversion of natural organic waste into fertilizer

- Considerable workload reduction in rural areas

- Visible improvement in rural hygiene

- Biogas is also used to produce electricity

- Biogas is also used to run an internal combustion engine in multifuel diesel engine 


\section{Results and Conclusion:}

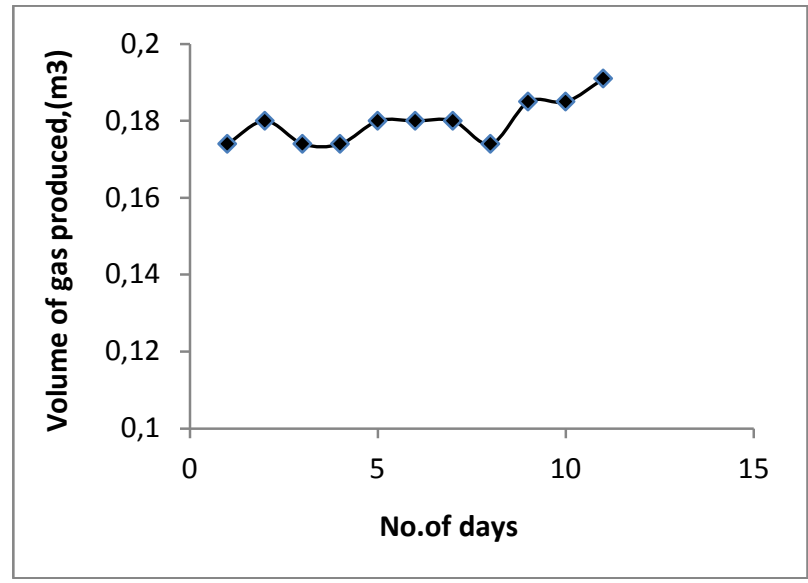

Fig 3.1 Effect of Temperature on Volume of gas produced

From graph 3.1 compared to cow dung and vegetable waste input, we observed maximum production of gas by addition of rice waste with cow dung as rice contain higher carbon content.

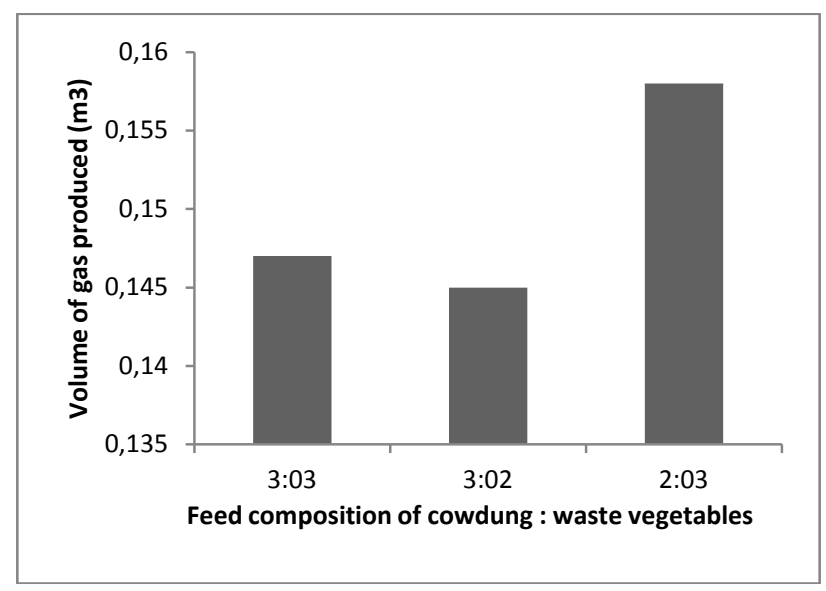

Fig 3.2 Effect of composition on volume of gas produced for waste vegetables

From graph 3.2 composition of waste vegetable with cow dung varies production of gas is also varied. Decrease in the composition of cow dung increases the production of gas.

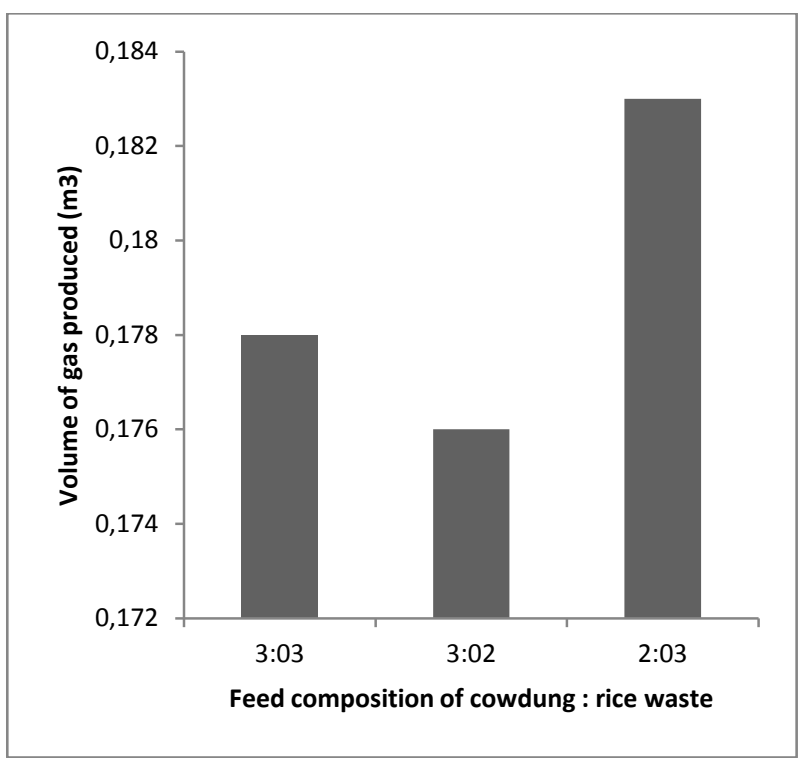

Fig 3.3 Effect of composition on volume of gas produced for rice waste

From graph 3.3 among the cow dung and waste vegetable the higher composition of rice waste gives maximum volume of gas. As composition of rice waste with cow dung varies production of gas is also varied. Decrease in the composition of cow dung increases the production of gas.

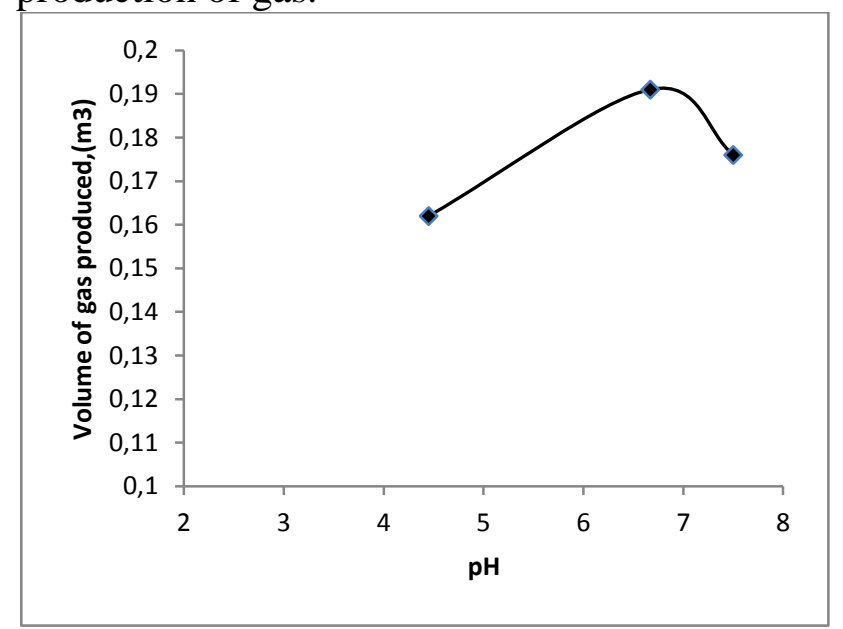

Fig 3.4 Effect of $\mathrm{pH}$ on gas production

From graph 3.4 as the $\mathrm{pH}$ value increases the production of gas also increases up to the $\mathrm{pH}$ of 6.5-7, there after production decreases because the active bacterial decomposition takes place

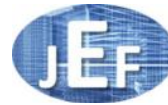


in that $\mathrm{pH}$. And we also increased the calorific value by passing the produced gas through scrubber. The calorific value which we obtained is $32.21 \mathrm{MJ} / \mathrm{kgk}$ which is sufficient enough to reduce the requirement of LPG.

\section{Conclusion:}

1. Biogas from biodegradable kitchen waste technology readily accepts highly digestible organic kitchen wastes and can be used in a household as well as hotels, its residues can be used as a fertilizer.

2. It concludes that to increase the production of biogas from kitchen waste, rice waste should mix with cow dung in 3:2 ratio, with considerable lesser amount of other kitchen waste and also by maintaining the $\mathrm{pH}$ of 6.2-6.5.

3. Calorific value is increased by passing the produced gas through scrubber. The calorific value which we obtained is $32.21 \mathrm{MJ} / \mathrm{kgk}$ which good enough to reduce the requirement of LPG.

\section{Acknowledgement:}

We would like to extend our sincere thanks to Karnataka State Council For Science And Technology, Indian Institute Of Science, Bangalore-12, for sponsoring us to carry out the project.

\section{References}

[1] Chand, AD, Natarajan, $U$ : Management information system for biogas development. Economic and Political Weekly.1987, Vol.22, No.48, pp M153M160.

[2] Daxiong, Q, Shuhua, G, Baofen, L, Gehua, and $\mathrm{W}, \mathrm{D}$ Diffusion and innovation in the Chinese biogas programme. World Development,1990 Vol.18, No.4, pp555563.
[3] FUEL: vol(88, 89, 74, 76, 94, 96). 1SSN 0016-236,

[4] GATE:Biogas technology in Sangli, India, Eschborn, 1999 Germany

[5] Joan M Ogend (2001) - Macmillan Encyclopodia of Energy - New York Gale Group -- 1st Ed. - Vol. 2

[6] Natural gas consumption reflects shifting sectoral patterns:may-16,2012. US energy information administration. 